\title{
Avaliação de complexo polivitamínico, polimineral, com aminoácidos, para leitões lactentes e recém desmamados: efeitos no desempenho, taxa de sobrevivência e índice de diarréia
}

\author{
An evaluation of a polivitaminic, polimineral complex associated with \\ essential amino acids to weaning and to weaned piglets: effects on the \\ performance, diarrhea incidence and mortality rate
}

\author{
Caio Abércio da Silva ${ }^{1^{*}}$; Ana Maria Bridi ${ }^{1}$; Piero da Silva Agostini ${ }^{2}$; Sylvia Luiza \\ Vinokurovas $^{2}$; Regina Maria Nascimento Augusto²; Larissa José Parazzi ${ }^{2}$
}

\section{Resumo}

\begin{abstract}
Foram realizados dois experimentos em uma granja comercial, nas fases de maternidade e creche, com o objetivo de avaliar os efeitos da administração de um complexo polivitamínico-polimineral com aminoácidos essenciais (Mod Plus ${ }^{\circledR}$ ) sobre o ganho de peso, a incidência de diarréia e a taxa de mortalidade dos leitões nestas fases. Na maternidade foram utilizados 324 leitões (entre 3 e 21 dias de idade) e na creche 295 animais (entre 21 e 63 dias de idade). Na maternidade foram definidos 4 tratamentos: leitões leves que não receberam suplementação nutricional polivitamínica-polimineral, leitões leves suplementados nutricionalmente ( $3 \mathrm{~mL}$ ao $3^{\circ}$ dia e reforço aos 10 dias de idade, via intramuscular), leitões pesados não suplementados e pesados suplementados nutricionalmente. Na creche os tratamentos foram: leitões leves que não receberam suplementação nutricional com polivitamínicos-poliminerais, leitões leves suplementados nutricionalmente com 1 dose ( $5 \mathrm{~mL}$ aos 21 dias de idade, via intramuscular), leitões leves suplementados nutricionalmente com 2 doses ( $3 \mathrm{~mL}$ aos 21 dias e aos 28 dias de idade, via intramuscular), leitões pesados não suplementados, leitões pesados suplementados nutricionalmente com 1 dose $(5 \mathrm{~mL}$ aos 21 dias de idade, via intramuscular) e leitões pesados suplementados nutricionalmente com 2 doses ( $3 \mathrm{~mL}$ aos 21 dias e aos 28 dias de idade, via intramuscular). O delineamento foi inteiramente casualizado em arranjo fatorial $2 \times 2$ na maternidade ( 2 condutas medicamentosas e 2 pesos iniciais) e $3 \times 2$ na creche ( 3 condutas medicamentosas e 2 pesos iniciais). Na maternidade os resultados apontaram melhora na taxa de mortalidade $(\mathrm{P}<0,05)$ para leitões suplementados nutricionalmente. Na creche houve melhora do peso final $(\mathrm{P}<0,05)$ para os animais tratados com 1 e com 2 doses de suplementação polivitamínicapolimineral em relação ao grupo controle (respectivamente, $20290 \mathrm{~g}$ e $20148 \mathrm{~g}$ versus $18782 \mathrm{~g}$ ). O uso deste complexo polivitamínico, polimineral, com aminoácidos essenciais, foi positivo sobre a taxa mortalidade na maternidade e sobre o desempenho na creche.

Palavras-chave: Vitaminas, minerais, leitões, performance, aminoácidos essenciais
\end{abstract}

\footnotetext{
1 Docentes. Universidade Estadual de Londrina. Departamento de Zootecnia. Campus Universitário, Londrina- PR. E-mail: casilva@uel.br.

2 Alunos do Curso de graduação em Medicina Veterinária da Universidade Estadual de Londrina, Londrina- PR.

* Autor para correspondência
} 


\begin{abstract}
The experiments were conducted on maternity and nursery phases in a commercial farm. The objective of the experiments was to evaluate the effects of administration of polivitaminic, polimineral complex associated with essential aminoacids (Mod Plus ${ }^{\circledR}$ ) on piglets weight gain, diarrhea incidence and mortality rate. 324 piglets with 3 to 21 days of age were used on the maternity phase and 295 weaned piglets of 21 to 63 days of age were used on the nursery phase. The animals were weighed at the beginning of the maternity phase and submitted to a 4 treatments: light piglets without polivitaminic and polimineral supplementation, light piglets supplemented with polivitaminic and polimineral complex $(3.0 \mathrm{~mL} \mathrm{IM}$ at 3 days of age followed by a 2 nd dose at 21 days of age), heavy piglets without polivitaminic and polimineral supplementation, and heavy piglets supplemented with polivitaminic and polimineral complex. Six treatments were defined on the nursery phase as follow: light piglets without polivitaminic and polimineral supplementation, light piglets supplemented with one dose of polivitaminic and polimineral complex (5.0 $\mathrm{mL}$ IM at 21 days of age), light piglets supplemented with two dosis of polivitaminic and polimineral complex ( $3.0 \mathrm{~mL}$ at 21 days of age followed by a $2 \mathrm{nd}$ dose, $3 \mathrm{~mL}$ IM, at 28 days of age), heavy piglets without polivitaminic and polimineral supplementation, heavy piglets supplemented with one dose of polivitaminic and polimineral complex (5.0 $\mathrm{mL}$ IM at 21 days of age), heavy piglets supplemented with two doses of polivitaminic and polimineral (Mod Plus ${ }^{\circledR}, 3.0 \mathrm{~mL}$ at 21 days of age followed by a $2 \mathrm{nd}$ dose, $3 \mathrm{~mL} \mathrm{IM}$, at 28 days of age). The experimental design was completely randomized under $2 \times 2$ factorial model to the maternity phase ( 2 medication conditions and 2 initial live weights) and $3 \times 2$ factorial model to the nursery phase ( 3 medication conditions and 2 initial live weights). At the maternity phase the mortality rate was better to supplemented group $(\mathrm{P}>0.05)$. At the nursery phase, animals that received 1 or 2 doses of supplementation complex presented a superior $(\mathrm{P}>0.05)$ final weight compared to a control group (respectively, 20290g and 20148g versus $18782 \mathrm{~g}$ ). The use of polivitaminic, polimineral complex associated with essential amino acids was positive to the mortality rate at the maternity phase and also over the animal performance at the nursery phase.
\end{abstract}

Key words: Live weight, piglets, pig, performance, mortality, vitamin

\section{Introdução}

A eficiência produtiva nas fases de maternidade e creche é tradicionalmente avaliada através do índice de desenvolvimento e da taxa de mortalidade dos leitões. Embora existam muitos recursos técnicos disponíveis para melhorar estes parâmetros, pelos inúmeros fatores de risco presentes, são comuns em algumas granjas elevados quadros de perda e de subdesenvolvimento dos leitões (SILVA et al., 1998; SILVA et al., 1999).

O baixo peso ao nascer é reconhecidamente um dos principais fatores envolvidos com o problema (HUGHES, 1992; SILVA et al., 1998). Leitões pequenos normalmente ingerem menos colostro e ganham menor aporte energético e imunitário, tornando-se mais expostos às enfermidades entéricas, além de apresentarem um desenvolvimento deficiente (SOBESTIANSKY et al., 1999).

Por esses motivos a sobrevida de leitões pequenos e não vigorosos diminui muito. Silva et al. (1998) observaram que as taxas de mortalidade são maiores para leitões mais leves ao nascimento, sendo que aqueles que nasceram com peso inferior a $1500 \mathrm{~g}$, apresentaram $25,6 \%$ de mortalidade até o desmame, comparado com 5,6\% de mortes para leitões nascidos com mais de $1500 \mathrm{~g}$.

Neste sentido, alguns procedimentos são comumente realizados para minimizar essas perdas, destacando-se a transferência de leitões entre porcas, a orientação das primeiras mamadas e a administração de solução glicosada (SOBESTIANSKY et al., 1999). Nesta linha, entretanto, a conduta da administração de complexos polivitamínicos e poliminerais e de aminoácidos essenciais aos lactentes, embora seja adotada em algumas granjas, é contestada por Mores et al. (1998) pelos efeitos inexpressivos que resultam sobre o crescimento e sobre a taxa de sobrevivência. 
Considerando a inter-relação das fases, todo o esforço dirigido aos leitões na maternidade para melhora do peso ao desmame tem repercussões importantes na fase de creche. Leitões mais pesados ao desmame sofrem menos com esta segregação e respondem com pesos mais elevados ao abate. Portanto, a necessidade de otimizar o peso ao desmame é condição sine qua non para o desenvolvimento do leitão (MORES et al., 1998).

$\mathrm{Na}$ fase de creche a conjunção de fatores adversos nos primeiros dias pós-desmame reduz o consumo de ração no período, diminui o ganho de peso (às vezes observa-se até a perda de peso) e expõe os leitões aos quadros diarréicos que podem evoluir a expressivas taxas de mortalidade (MAENZ; PATIENCE; WOLYNETZ, 1993).

A redução dos fatores de risco na creche, principalmente nas primeiras semanas pós-desmame, é fundamental para o êxito dos resultados finais. Não obstante, recursos outros como a administração de soluções fisiológicas ou glicosadas via água, umedecimento da ração (SILVA et al., 1999) e uso de complexos vitamínicos e minerais podem ser adotados para otimizar esta fase.

Quanto ao uso parenteral destes complexos vitamínicos e minerais, sabe-se que o procedimento é comumente voltado à compensação de possíveis deficiências destes, decorrentes da redução típica de consumo por que passa o leitão nesta fase. A vitamina $\mathrm{D}$ e até certo ponto a vitamina A tem suas formas ativas sintetizadas pelo organismo e liberadas de acordo com as necessidades do animal. A deficiência de vitamina E, contudo, é mais comum em animais jovens e pode estar associada também à privação de alimento. Esta mesma linha de entendimento aplicase também para alguns aminoácidos essenciais (PHILLIPS, 1983).

Com relação às vitaminas hidrossolúveis, estas constituem um grupo heterogêneo de micronutrientes necessários para os animais. Na maioria dos casos, estas vitaminas são ingeridas sob a forma de componentes naturais da dieta ou são sintetizadas pelos microrganismos gastrintestinais. Pode-se supor que um grande número de animais não necessita de suplementação profilática adicional desses micronutrientes. A utilização de vitaminas hidrossolúveis normalmente é de caráter profilático ou de apoio, diante da depressão no consumo observada na fase. Nesta conduta, devem-se levar em conta também que estas não são armazenadas no organismo em grandes quantidades e tampouco por períodos prolongados (PHILLIPS, 1983).

Neste sentido, os complexos multivitamínicos, multiminerais, com a presença de alguns aminoácidos essenciais têm sido empregados em situações imediatas ao nascimento do leitão e mais intensamente no pós-desmame.

$\mathrm{Na}$ prática, a polêmica quanto à eficácia deste procedimento profilático ou de apoio terapêutico ainda persiste e poucos trabalhos científicos que abordam o tema são conduzidos. Assim, o objetivo deste trabalho foi avaliar procedimentos de uso de um complexo polivitamínico, polimineral, com aminoácidos essenciais, sobre o desenvolvimento de leitões na maternidade e no pós-desmame e seus efeitos sobre a taxa de mortalidade e a incidência de diarréia.

\section{Material e Métodos}

O presente trabalho foi desenvolvido em uma granja comercial de suínos, localizada no município de Apucarana, estado do Paraná, com 300 matrizes da linhagem Penarlan.

Foram envolvidos nas avaliações, os setores de maternidade e creche. Ambas as fases utilizavam o manejo de alojamento contínuo e caracterizavam-se por serem edificadas em alvenaria e apresentarem piso compacto com cama de maravalha.

A maternidade era composta por celas parideiras, com gaiolas e escamoteadores providos de aquecimento com lâmpada elétrica de 100 watts, bebedouro tipo chupeta e comedouro específicos para os leitões. 
Os leitões lactentes receberam os manejos de corte e desinfecção do umbigo, corte de cauda e dentes, administração de ferro dextrano via parenteral e foram submetidos à transferência entre as matrizes somente em situações de real necessidade. A alimentação das matrizes durante todo o período lactacional foi à vontade.

$\mathrm{Na}$ creche as baias eram dimensionadas para 50 leitões (oferecendo $0,5 \mathrm{~m}^{2}$ de área por animal) e dispunham de um abafador com $2 \mathrm{~m}^{2}$ de área, comedouro semi-automático e 2 bebedouros tipo chupeta. Os lotes foram formados no dia do desmame (realizado em média aos 21 dias de idade). Não foi considerada na formação dos lotes a separação pelo sexo, uma vez que até o final desta fase comumente não se observam diferenças entre machos castrados e fêmeas.

Como manejo alimentar, foram utilizadas duas rações: pré-inicial (oferecida dos sete aos 42 dias de idade) e inicial (administrada dos 43 aos 63 dias de idade). Ambas foram fornecidas à vontade. A composição das rações e os níveis nutricionais estão apresentados na Tabela 1.

Tabela 1. Composição centesimal das rações pré-inicial e inicial utilizadas durante o período experimental.

\begin{tabular}{|c|c|c|}
\hline \multirow[t]{2}{*}{ Ingredientes (\%) } & \multicolumn{2}{|c|}{ Rações } \\
\hline & Pré-inicial & Inicial \\
\hline Milho & 42,00 & 61,00 \\
\hline Farelo de soja & 29,50 & 29,00 \\
\hline Aveia grão & 5,00 & - \\
\hline Óleo degomado & 1,50 & 1,00 \\
\hline Leite em pó & 2,50 & - \\
\hline Soro de leite em pó & 7,50 & - \\
\hline Biomix 12\%1 & 12,00 & - \\
\hline Startermix $9 \%$ & - & 9,00 \\
\hline Total & 100,00 & 100,00 \\
\hline \multicolumn{3}{|l|}{ Valores Calculados } \\
\hline Proteína Bruta (\%) & 19,400 & 18,450 \\
\hline Energia Digestível (Kcal/Kg) & 3.310 & 3.270 \\
\hline Fibra bruta $(\%)$ & 3,226 & 3,074 \\
\hline Cálcio (\%) & 0,830 & 0,870 \\
\hline Fósforo total (\%) & 0,657 & 0,613 \\
\hline Lisina $(\%)$ & 1,116 & 1,034 \\
\hline Extrato etéreo (\%) & 3,451 & 3,329 \\
\hline
\end{tabular}

${ }^{1}$ Núcleo Biomix 12\% (valores calculados por kg de produto): vit. A, 83.333 UI; vit. B12, 166,50mcg; vit.D3, 16.666 UI; vit. B12, 166,5mg; vit. E, 291.50mg; vit. K3, 16,52mg; ácido nicotínico, 250,3mg; ácido pantotênico, 83mg; colina, 4166,50mg; vit. B6, $25 \mathrm{mg}$; vit. B9, 8mg; Biotina, $125 \mathrm{mg}$; manganês, 250mg; cobre, 1.041,50mg; zinco, 833mg; ferro, 416,50mg; iodo, 3,33; selênio, 0,83mg; Ca, 52g; flúor, $252 \mathrm{mg}$; sódio, $7 \mathrm{~g}$, cobalto, 3,33mg.

${ }^{2}$ Núcleo Startermix 9\% (valores calculados por kg de produto): vit. A111.099.8 UI; vit. B12, 221.98mcg; vit.D3, 22.219,7 UI; vit. B12, 44,32mg; vit. E, 333.3mg; vit. K3, 22mg; ácido nicotínico, 333,3mg; ácido pantotênico, 110,99mg; colina, 221,78mg; vit. B6, 33,33 mg; vit. B9, 11mg; Biotina, 166,65 mg; manganês, 333,30mg; cobre, 1.388,53mg; zinco, 1.110,89mg; ferro, 555,28mg; iodo, 4,43; selênio, 1,11mg; Ca, 83g; flúor, 342mg; sódio, 9g, cobalto, 4,43mg. 
A avaliação na fase de maternidade envolveu 324 leitões do $3^{\circ}$ dia de vida até o desmame (realizado aos 21 dias de idade). Metade dos animais recebeu, via parenteral, uma suplementação nutricional polivitamínica-polimineral, com aminoácidos (Mod Plus ${ }^{\circledR}$ - Agener União Saúde Animal) e os demais ficaram isentos desta suplementação. A composição do produto, expressa na concentração do princípio para cada $100 \mathrm{~mL}$, apresentava: vitamina E acetato (1000 UI), vitamina B12 (5 mg), monoglutamato de sódio (420 mg), cloridrato de L-lisina (1.000 mg), glicina (420 mg), DL-metionina (210 mg), cloridrato de L-arginina (200 mg), L-valina (200 mg), Ltriptofano (200 mg), cloridrato de L-histidina (210 mg), L-leucina (210 mg), selenito de sódio anidro (25 mg), sulfato de cobre (2 mg), cloreto de cobalto $(13 \mathrm{mg})$, cloreto de sódio $(42 \mathrm{mg})$, cloreto de zinco $(10 \mathrm{mg})$, hipofosfito de cálcio $(1.500 \mathrm{mg})$ e cloreto de magnésio (210 mg).

Dentro de cada leitegada todos os leitões foram pesados ao $3^{\circ}$ dia e identificados através do sistema australiano, sendo classificados em leitões com peso inferior a $1500 \mathrm{~g}$ (definidos como leves) e com peso igual ou superior a $1500 \mathrm{~g}$ (leitões pesados)

A partir da pesagem e da condição de suplementação nutricional dispensada, foram estabelecidos aleatoriamente os seguintes tratamentos experimentais:

T1 - leitões leves sem suplementação nutricional; T2 - leitões leves com suplementação nutricional; T3 - leitões pesados sem suplementação nutricional; T4 - leitões pesados com suplementação nutricional.

Durante a amamentação os leitões foram manejados indistintamente aos tratamentos à que pertenciam. As mortes ao longo do experimento foram registradas e suas causas notificadas, sendo: fraqueza, esmagamento, diarréias, artrite, encefalite e outras.

Para a avaliação do índice de diarréia foi utilizada a técnica proposta por Mores et al. (1990) e Soncini e
Madureira Júnior (1998). Os leitões foram examinados individualmente, duas vezes ao dia, às 9:00 e às 18:00 horas, e as fezes classificadas em normais ou pastosas (sem diarréia) e líquidas (com diarréia).

Aos 21 dias de idade, os leitões foram pesados e desmamados, definindo a estimativa do ganho de peso médio no período.

Para os parâmetros peso inicial e final e para os índices de diarréia e mortalidade, cada leitão representou uma repetição.

O delineamento foi inteiramente casualizado, num modelo fatorial $2 \times 2$, correspondendo a 2 condutas terapêuticas (suplementados e não suplementados nutricionalmente) e 2 situações de peso (leitões leves e pesados). Aos dados de desempenho foi realizada a análise de variância e as médias submetidas ao teste de Tukey. Aos demais dados foi utilizado o teste de Qui quadrado.

$\mathrm{Na}$ fase de creche foram utilizados outros 295 leitões, sendo estes avaliados a partir do desmame (realizado aos 21 dias de idade) até os 63 dias de idade (final do período de creche).

Como protocolo foram utilizadas duas condutas de administração do suplemento polivitamínicopolimineral com aminoácidos essenciais: uma dose ao desmame ( $5 \mathrm{~mL}$ intramuscular) e 2 doses (uma dose ao desmame, correspondente a $3 \mathrm{~mL}$ via intramuscular, e a segunda dose 7 dias após, $3 \mathrm{~mL}$ intramuscular).

Ao desmame os leitões foram pesados individualmente e subdivididos em 2 grupos: leves (com peso inferior a $5000 \mathrm{~g}$ ) e pesados (peso igual ou superior a $5000 \mathrm{~g}$ ).

Baseado no peso ao desmame e nos protocolos de uso do produto, foram estabelecidos os seguintes tratamentos experimentais na fase de creche:

T1 - Leitões leves sem suplementação nutricional; T2 - Leitões leves submetidos a uma dose de suplementação nutricional; 
T3 - Leitões leves submetidos a duas doses de suplementação nutricional;

T4 - Leitões pesados sem suplementação nutricional; T5 - Leitões pesados submetidos a uma dose de suplementação nutricional;

T6 - Leitões pesados submetidos a duas doses de suplementação nutricional.

Para reconhecimento dos tratamentos recebidos os leitões foram identificados pelo sistema australiano. Nas baias os leitões de todos os tratamentos foram mantidos juntos até os 63 dias de idade (término do experimento), onde foram individualmente pesados, obtendo-se o peso final e o ganho de peso no período.

Diariamente foi notificada a ocorrência de morte e registrada a sua causa (fraqueza, diarréia, pneumonia, encefalite e outras). Nos primeiros 10 dias pós-desmame, através de um exame individualizado nos animais, verificou-se a presença de diarréia para cálculo da taxa desta através da metodologia proposta por Mores et al. (1990) e Soncini e Madureira Júnior (1998).

Para parâmetros peso inicial e final, e para os índices de diarréia e mortalidade, cada leitão representou uma repetição.

O delineamento foi inteiramente ao acaso, num modelo fatorial $3 \times 2$, sendo 3 condutas terapêuticas (não suplementados nutricionalmente, suplementados com 1 dose e suplementados com 2 doses) e 2 pesos iniciais ao desmame (leves e pesados). Aos dados de desempenho foram realizadas análises de variância e as médias submetidas ao teste de Tukey. Aos demais dados foi utilizado o teste de Qui quadrado.

\section{Resultados e Discussão}

Os resultados do desempenho dos leitões na maternidade estão demonstrados na Tabela 2. Através da análise binária da variância não foi observado efeito das interações.

Tabela 2. Efeitos do uso de suplementação nutricional em leitões lactentes sobre o peso ao desmame (21 dias) e sobre ganho de peso no período.

\begin{tabular}{lccc}
\hline Fatores & \multicolumn{3}{c}{ Parâmetros } \\
& Peso inicial (g) & Peso ao desmame (g) & Ganho de peso (g) \\
\hline Medicação & $1652 \pm 437$ & $5877 \pm 1016$ & 4225 \\
Sem suplementação & $1645 \pm 412$ & $5645 \pm 1236$ & 4000 \\
Com suplementação & & & \\
Peso & $1207 \mathrm{~b} \pm 212$ & $5022 \pm 1057$ & 3815 \\
Leitões leves & $1908 \mathrm{a} \pm 277$ & $6144 \pm 984$ & 4236 \\
Leitões pesados & 25,78 & 19,77 & - \\
Coeficiente de variação (\%) & & & \\
\hline
\end{tabular}

* para cada parâmetro, letras diferentes na mesma coluna, para o mesmo fator, diferem entre si pelo teste de Tukey $(\mathrm{P}<0.05)$.

Observa-se que tanto para o fator peso quanto para o fator medicação não houve diferença $(\mathrm{P}>0,05)$ entre os grupos para o peso ao desmame (peso final), mesmo considerando que os leitões mais pesados ao $3^{\circ}$ dia de vida (início do experimento) apresentavam diferenças significativas em relação ao grupo de leitões leves.
Contrariamente aos resultados observados, sabese que leitões mais pesados ao nascimento têm melhores condições de competição para mamar em relação aos leves, ingerindo mais colostro e leite ao longo da fase.

Quanto à ausência de efeitos no desempenho de leitões suplementados nutricionalmente em relação 
aos não suplementados, os resultados identificam-se com a afirmação de Mores et al. (1998), que tratam que para lactentes qualquer tentativa de aporte nutricional, através de uso de complexos vitamínicos e minerais, não resulta em melhora no desempenho.

Sabe-se também que leitões ou leitegadas mais pesadas ao desmame são resultados principalmente da maior competência leiteira da matriz, sendo pequena a influência do potencial genético dos leitões ou de alguma conduta de suplementação vitamínica/ mineral orientada para estes.

Quanto à taxa de mortalidade (Tabela 3), para os fatores analisados, leitões suplementados e leitões mais pesados no início do experimento apresentaram, respectivamente, vantagens $(\mathrm{P}<0,05)$ em relação aos não suplementados e aos leves.

Tabela 3. Taxa de mortalidade e índice de diarréia na maternidade de leitões lactentes de acordo com os fatores experimentais.

\begin{tabular}{|c|c|c|}
\hline \multirow[t]{2}{*}{ Fatores } & \multicolumn{2}{|c|}{ Parâmetros } \\
\hline & Mortalidade (\%) & Diarréia (\%) \\
\hline \multicolumn{3}{|l|}{ Medicação } \\
\hline Sem suplementação & $16,66 b$ & $11,85 \mathrm{a}$ \\
\hline Com suplementação & $7,84 \mathrm{a}$ & $6,84 \mathrm{a}$ \\
\hline \multicolumn{3}{|l|}{ Peso } \\
\hline Leitões leves & $15,52 b$ & $8,59 a$ \\
\hline Leitões pesados & $6,74 a$ & $10,10 \mathrm{a}$ \\
\hline
\end{tabular}

*para cada parâmetro, letras diferentes na mesma coluna, para o mesmo fator diferem entre si pelo teste de quiquadrado $(\mathrm{P}<0.05)$.

As duas principais causas de morte observadas foram o esmagamento e a fraqueza, representados, respectivamente, por $32,75 \%$ e $67,25 \%$ do total de perdas.

Quanto a diarréia (Tabela 3), não se verificou diferenças $(\mathrm{P}>0,05)$ entre os tratamentos para os fatores avaliados.

As baixas ingestões de leite, comumente observadas para leitões leves, influenciam negativamente os índices de sobrevivência e diarréia
(AUMAITRE, 1985, AHERNE, 1991). Contudo, contrariando as afirmações de Mores et al. (1998), que tratam que o uso de complexos polivitamínicos e poliminerais é ineficiente sobre a redução da taxa de mortalidade, observou-se que a suplementação foi positiva sobre este parâmetro.

Quanto à fase de creche, os resultados do uso da suplementação sobre o desempenho estão indicados na Tabela 4, onde não foram observados efeitos de interação entre os tratamentos.

Tabela 4. Efeitos do uso de suplementação nutricional em leitões na fase de creche sobre o peso aos 63 dias de idade (peso final) e o ganho de peso no período.

\begin{tabular}{lccc}
\hline Fatores & Parâmetros & \\
& Peso inicial (g) & Peso final (g) & Ganho de peso (g) \\
\hline Medicação & $5150 \mathrm{a} \pm 652$ & $18946 \mathrm{~b} \pm 3958$ & 13796 \\
Sem suplementação & $5124 \mathrm{a} \pm 619$ & $20290 \mathrm{a} \pm 3449$ & 15166 \\
Com suplementação (1 dose) & $5082 \mathrm{a} \pm 608$ & $20119 \mathrm{a} \pm 3749$ & 15037 \\
Com suplementação (2 doses) & & & \\
Peso & $4801 \mathrm{~b} \pm 470$ & $19142 \mathrm{a} \pm 3419$ & 14341 \\
Leitões leves & $5642 \mathrm{a} \pm 480$ & $20423 \mathrm{a} \pm 3736$ & 14781 \\
Leitões pesados & 4,03 & 18,90 & - \\
Coeficiente de variação (\%) & &
\end{tabular}

* para cada parâmetro, letras diferentes na mesma coluna, para o mesmo fator diferem entre si pelo teste de Tukey $(\mathrm{P}<0.05)$. 
Os dados indicam que os grupos que receberam suplementação apresentaram melhor peso final na saída de creche $(\mathrm{P}<0,05)$, independente do número de doses administradas. Com relação ao ganho de peso no período, os grupos suplementados com uma e duas doses apresentaram, respectivamente, resultados superiores em 9,93 e 8,99\% comparados com o grupo controle.

Para o fator peso, mesmo diante de um peso inicial superior para o grupo de leitões pesados, não houve diferença $(\mathrm{P}>0,05)$ entre os grupos ao final do período experimental e tampouco valores muito distintos para o ganho de peso. Este quadro contraria o conceito de que leitões mais pesados ao desmame têm melhor desempenho até o final da fase de creche.

As indicações de produtos polivitamínicos e poliminerais se identificam exatamente com este momento. A conduta lógica da administração destes compostos envolve o fato de que algumas vitaminas (principalmente do complexo B) não são armazenadas em quantidades suficientes no organismo e tampouco por períodos prolongados, que a diminuição da ingestão de alimento (que no desmame pode perdurar como crítico por até 3 semanas) reduz a taxa de entrada destes nutrientes no animal, e que em condições patológicas (diarréias por exemplo, comuns no pós-desmame) e nas alterações metabólicas, alguns nutrientes como as vitaminas e os minerais, entre outros, são esgotados mais rapidamente (PHILLIPS, 1983). Paralelamente, alguns macros e microminerais são requeridos sob níveis tão baixos que em alguns casos suas dietas não os provêm suficientemente (NATIONAL RESEARCH COUNCIL, 1998).

Alguns estudos sugeriram que os níveis indicados pelo National Research Councill de 1988, principalmente para as vitaminas do complexo $\mathrm{B}$ (riboflavina, niacina, ácido pantotênico e vitamina B12), são insuficientes para a máxima performance do recém desmamado ou para leitões com alta capacidade de deposição de tecido magro, (WILSON et al., 1991, WILSON et al., 1992, WILSON et al.,
1993 e STAHLY et al., 1995 apud NATIONAL RESEARCH COUNCIL, 1998). A administração de doses de vitamina do complexo B sob níveis entre duas a dez vezes o valor estimado pelo National Research Councill de 1988, tenderam a melhorar o índice de crescimento na fase, sugerindo que os níveis de exigências destas vitaminas têm se modificado no leitão recém-desmamado (NATIONAL RESEARCH COUNCIL, 1998).

Quanto à mortalidade e à incidência de diarréia na creche, os resultados indicam que não houve diferença $(\mathrm{P}>0,05)$ para nenhum tratamento quer para o fator suplementação quer para o fator peso inicial. A taxa média de mortes, considerando todos os tratamentos, foi de $3,75 \%$, sendo todas atribuídas à pneumonia como causa.

O fato dos grupos de leitões leves e pesados apresentarem semelhantes $(\mathrm{P}>0,05)$ taxas de mortalidade contraria o conceito de que os leitões mais leves são mais sensíveis aos fatores de risco e, portanto, mais sujeitos aos quadros diarréicos comuns na fase (MADEC; JOSSE, 1983).

Diante dos resultados obtidos observa-se que a utilização de suplementação na maternidade não resultou em efeitos no ganho de peso, mas influenciou decisivamente a taxa de mortalidade, melhorando este índice.

$\mathrm{Na}$ fase de creche a utilização de suplementação, independente do número de doses, foi suficiente para melhorar o peso ao final da fase, porém não houve repercussões na redução da mortalidade e na incidência de diarréia.

\section{Conclusões}

A utilização de suplementação polivitamínica e polimineral é eficaz na redução da taxa de mortalidade de leitões em fase de maternidade. Na creche, a administração complexos polivitamínicos e polimerais, sob uma ou duas doses, melhora o desenvolvimento dos leitões, elevando o peso na saída da fase. 


\section{Referências}

AHERNE, F. El estrogen en los lechones reduce la mortalidad. International Pigletter, South St. Paul, v.4, n.11,p.16, 1991.

AUMAITRE, A. Algumas informações básicas sobre a biologia dos leitões recém-nascidos objetivando o aumento da taxa de sobrevivência. A Hora Veterinária, Porto Alegre, v.4, n.28, p.21-28, 1985.

HUGHES, P. E. Postnatal care in pigs. British Society of Animal Production, Midlothian, Scotland, v.15, p.146-167, 1992.

MADEC, F.; JOSSE, J. Influence of environmental factors on outset of digestive disorders of weaned piglet. Annales de Recherches Veterinaires, Versailles, v.14, n.4, p.456$462,1983$.

MAENZ, D. D.; PATIENCE, J. F.; WOLYNETZ, M. S. Effect of water on the performance of newly weaned pigs offered medicated and unmedicated feed. Canadian Journal of Animal Science, Ottawa, v.3, n.73, p.669-672, 1993.

MORES, N.; MARQUES, J. L.; SOBESTIANSKY, J.; OLIVEIRA, A.; COELHO, L. S. S. Influência do nível protéico e/ou acidificação da ração pós-desmame em leitões causada por Escherichia coli. Pesquisa Veterinária Brasileira, Rio de Janeiro, v.10, n.3/4, p.8588, 1990.

MORES, N.; SOBESTIANSKY, J.; WENTZ, I.; MORENO, A. M. Manejo do leitão desde o nascimento até o abate. In: SOBESTIANSKY, J.; WENTZ, I.; SILVEIRA, P. R. S.; SESTI, A. C. (Ed.). Suinocultura Intensiva: produção, manejo e saúde do rebanho. Brasília: EMBRAPA, 1998.
NATIONAL RESEARCH COUNCIL.. Nutrient requirements of swine. 10.ed. Washington: National Academy Press, 1998.

PHILLIPS, W. R. Farmacologia nutricional. In: MEYER JONES, L.; BOOTH, N. N.; McDONALD, L. Farmacologia e Terapêutica em Medicina Veterinária. 4.ed. Rio de Janeiro: Guanabara Koogan, 1983. p.552-593.

SILVA, C. A.; BRITO, B. G.; MORES, N.; AMARAL, A. L. Fatores de risco relacionados com o desempenho de leitões lactentes em granjas de suínos da região norte do Paraná. Ciência Rural, Santa Maria, v.28, n.4, p.677-681, 1998.

SILVA, C. A.; BRITO, B. G.; MORES, N.; AMARAL, A. L.Ecopatologia da diarréia pós-desmame em granjas de suínos da região norte do Paraná. Ciência Rural, Santa Maria, v.29, n.1, p.39-43, 1999.

SOBESTIANSKY, J.; BARCELLOS, D. E. S. N.; MORES, N.; OLIVEIRA, S. J.; CARVALHO, L. F. O.; MORENO, A. M.; ROEHE, P. M.. Clínica e patologia suina. 2.ed. Goiânia: Art 3, 1999.

SONCINI, R. A.; MADUREIRA JÚNIOR, S. E. Monitorias sanitárias. In: SOBESTIANSKY, J.; WENTZ, I.; SILVEIRA, P. R. S.; SESTI, A. C. (Ed.) Suinocultura Intensiva: produção, manejo e saúde do rebanho. Brasília: EMBRAPA, 1998. 
